\title{
No-Show Patients and the Triple Aim
}

\author{
Martin F. Shapiro, MD, $P h D^{1,2}$ \\ 'Department of Medicine, Division of General Internal Medicine and Health Services Research, University of California, Los Angeles, Los Angeles, \\ CA, USA; ${ }^{2}$ Department of Health Policy \& Management, Fielding School of Public Health, University of California, Los Angeles, Los Angeles, CA, USA.
}

J Gen Intern Med 30(10): 1392-3

DOI: $10.1007 / \mathrm{s} 11606-015-3404-5$

(c) Society of General Internal Medicine 2015

$\mathrm{T}$ he paper by Hwang et al. ${ }^{1}$ takes on an important and understudied problem in medical practice: the impact of patients missing appointments on clinical outcomes and services use. Hwang et al. found that in an academic practice, patients above the 90th centile of missed appointments had substantially poorer control of diabetes and hyperlipidemia and lower completion of prevention procedures, as well as higher emergency department and hospital utilization. Even those above the 75th centile had outcomes in the same direction, although of lesser magnitude. This is a very important paper. Policy-makers need to play close attention to these findings, because it calls for remedies at levels of both clinical practice and health policy. To understand why, allow me to illustrate with a case.

More than 25 years ago, a woman came to my clinic complaining of a terrible headache. Her systolic blood pressure reading was higher than the $308 \mathrm{~mm} \mathrm{Hg}$ measurable with a mercury sphygmomanometer; her diastolic BP was $186 \mathrm{~mm}$. She was convinced that there was something in her head that been put there by microwaves emitted by her hostile neighbor. I explained to her that her blood pressure was dangerously high and that she needed to be hospitalized. She refused, having had bad experiences in hospitals before, apparently related to her chronic mental illness. She agreed to take some medicine and come back and see me three days later. Eventually, I was able to work her blood pressure down to something in the range of $150 / 100$. Over the ensuing quarter century, I could never fully control her blood pressure, which ranged mostly between 160 and $180 / 95$ and 110 . On rare occasions, we got to normal values, but they never lasted. A major problem was that she missed at least $80 \%$ of her appointments. She lived far away and could not get transportation, she had urgent matters to address with regards to bills to pay, and so on. When she would come in, she was often 2 hours late and frequently had stopped taking one or another medication. We sometimes discussed prevention

Published online June 17, 2015 procedures, and I managed to induce her to have a mammogram once every 4 or 5 years.

The administrator of my clinic told me that I should discharge her from my practice because of her horrid nonadherence to appointments. I would not do that. I knew that she trusted me as much as anyone. (She always asked for a copy of my note and made sure that I had not said anything about her having a mental illness.) If I abandoned her, she would not go to another doctor and her hypertension would kill her. Eventually, she developed atrial fibrillation. I tried to treat her with warfarin, but her INR was rarely more than 1.2. She would miss many appointments in the anticoagulation clinic, then show up, requiring me to re-register her because they felt that they could not take care of someone so nonadherent. She had two minor strokes and largely recovered from them. She began to come in for more of her appointments, but still missed at least half of them. One day she showed up in clinic, announced that I had cared for her for 25 years, and gave me a gift and a card saying that I had saved her life.

The intent of current policy to improve quality and outcomes of care while lowering costs ${ }^{2}$ is admirable, but current quality metrics give physicians and health systems substantial incentives to steer clear of patients such as mine. What accountable care organization (ACO) would want to attract or retain them? Hwang and his coauthors suggest that high visit no-show rates should be used to identify patients for whom additional interventions are needed to improve quality and reduce costs. I agree, but no combination of structural or process changes, behavioral interventions, care coordination programs or home visits will produce good outcomes for such patients at costs comparable to those from middle class neighborhoods who are less likely to have the kind of complex social, psychological and medical problems that contribute to not showing up. ACOs operate under incentives to structure their systems to make it less likely that psychosocially complex patients such as mine will ever come through their doors. Doctors who are paid for performance will not despair at the loss of a patient with a glycosylated hemoglobin level of 11 , chronically uncontrolled blood pressure, or any other suboptimal outcome that undermines their performance scores.

Certainly, we should find ways of encouraging better quality of care, but that should not be done in ways that 
penalize providers of complex patients who often are multiply disadvantaged. All of the academic health systems that I know (other than those based at public hospitals) possess the talent to care for such patients, but also the talent to avoid them. We must not create systems that allow them to make the wrong choice. Rather than helping to diminish health disparities, pay for performance and so-called accountable care as currently operationalized are likely to contribute to the perpetuation of the kind of stark inequality across demographic groups that distinguishes American health care from that in other nations with advanced economies. ${ }^{3,4}$ Let's scrap these perverse incentives, and replace them with something that much more fully accounts for the complexity and challenges involved in the care of those who need our help the most, keeping in mind the words of Emma Lazarus inscribed on base of the Statue of Liberty.
Conflict of Interest: The author has no conflict of interest regarding the subject or content of this article.

Corresponding Author: Martin F. Shapiro, $M D, P h D$; Department of Medicine, Division of General Internal Medicine and Health Services ResearchUniversity of California, Los Angeles, 911 Broxton Ave, Los Angeles, CA 90024, USA (e-mail: mfshapiro@mednet.ucla.edu).

\section{REFERENCES}

1. Hwang AS, Atlas SJ, Cronin P, Ashburner JM, Shaw SJ, He W, Hong CS. Appointment "No-shows" are an independent predictor of subsequent quality of care and resource utilization outcomes. J Gen Intern Med. 2015. doi:10.1007/s11606-015-3252-3.

2. Berwick DM, Nolan TW, Whittington J. The triple aim: care, health, and cost. Health Aff. 2008;27(3):759-69.

3. Pollack CE, Armstrong K. Accountable care organizations and health care disparities. JAMA. 2011;305(16):1706-7.

4. Casilano LP, Elster A, Eisenberg A, Lewis E, Montgomery J, Ramos D. Will pay-for-performance and quality reporting affect health care disparities? Health Aff. 2007;26(3):w405-14. 